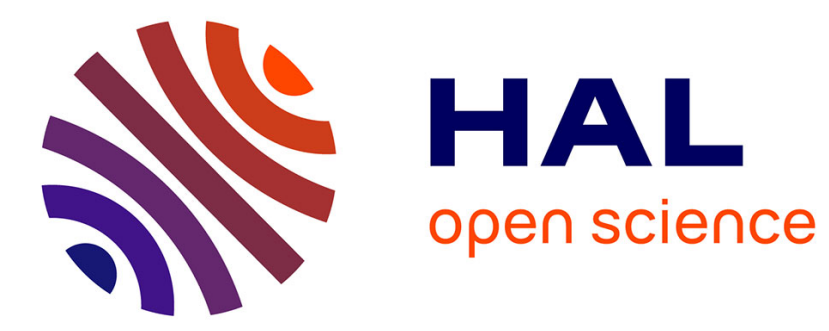

\title{
The Identification of Radial Structure Peaks of EXAFS Fourier Transform of NiO Dispersion Phase
}

\author{
X. Cai, Y. Xie, Zhuoxiang Ren, Y. Tang, T. Tanaka
}

\section{To cite this version:}

X. Cai, Y. Xie, Zhuoxiang Ren, Y. Tang, T. Tanaka. The Identification of Radial Structure Peaks of EXAFS Fourier Transform of NiO Dispersion Phase. Journal de Physique IV Proceedings, 1997, 7 (C2), pp.C2-899-C2-900. 10.1051/jp4:1997271 . jpa-00255354

\section{HAL Id: jpa-00255354 https://hal.science/jpa-00255354}

Submitted on 1 Jan 1997

HAL is a multi-disciplinary open access archive for the deposit and dissemination of scientific research documents, whether they are published or not. The documents may come from teaching and research institutions in France or abroad, or from public or private research centers.
L'archive ouverte pluridisciplinaire HAL, est destinée au dépôt et à la diffusion de documents scientifiques de niveau recherche, publiés ou non, émanant des établissements d'enseignement et de recherche français ou étrangers, des laboratoires publics ou privés. 


\title{
The Identification of Radial Structure Peaks of EXAFS Fourier Transform of NiO Dispersion Phase
}

\author{
X. Cai, Y. Xie, Z. Ren, Y. Tang and T. Tanaka* \\ Department of Chemistry, Peking University, Beijing 100871, P.R. China \\ * Department of Molecular Engineering, Kyoto University, Sakyo-ku, Kyoto 606-01, Japan
}

\begin{abstract}
A comparison of backscattering amplitudes and APCFT of XAFS of dispersed and crystalline NiO were used to identify radial structural peaks. The results show that there are coordination peaks in the FT function of dispersed phase corresponding to the first, third and forth $\mathrm{Ni}-\mathrm{Ni}$ coordination shelis in the crystalline $\mathrm{NiO}$, although their area may very different depending on the loadings of NiO. But there are no peak corresponding to the second Ni-Ni coordination shell of $\mathrm{NiO}$. It is to say that the second $\mathrm{Ni}-\mathrm{Ni}$ shell in crystalline $\mathrm{NiO}$ disappears as in spinel and the other $\mathrm{Ni}-\mathrm{Ni}$ coordination shells may still exist when NiO disperses on the surface of support. It also implies that the structure of surface-dispersed NiO has both similarity and difference to $\mathrm{NiAl}_{2} \mathrm{O}_{4}$ or $\mathrm{NiO}$.
\end{abstract}

\section{Introduction}

XAFS can give abundant structural information quantitatively, moreover, the information about coordination species can be obtained qualitatively in some cases, too. In general, little attention is paid to the later one which is the base of the former. If the radial stnctural peaks are not been assigned correctly, it is impossible to get the true quantitative information. Especially, for the case that the system has several coordination shells with close distances, it is more important to distinguish the radial peaks and to develop the qualitative studies on coordination atom species. In this paper, comparison of backscattering amplitudes [1] (including $\left(\mathrm{N} / \mathrm{R}^{2}\right) \mathrm{e}^{-2 \sigma 2} \mathrm{e}^{2 t / \lambda}$ ), APCFT [2] (Amplitude and phase shift corrected Fourier transform) method were carried out on $\mathrm{NiO}$ / $\mathrm{g}-\mathrm{Al}_{2} \mathrm{O}_{3}$ dispersion system to discriminate its structure peaks.

\section{Results and Discussion}

$\mathrm{NiO}$ has the structure of $\mathrm{NaCl}$ type. Its radial peaks have been assigned very well yet [1]. When $\mathrm{NiO}$ is dispersed on the support, the diffraction pattern of $\mathrm{NiO}$ disappears. But most Ni-Ni coordination peaks corresponding to crystalline NiO still exist (the position shifts slightly and intensity decreases) except the second $\mathrm{Ni}-\mathrm{Ni}$ coordination shell (Ni-Ni(2) corresponding to the second $\mathrm{Ni}$ $\mathrm{Ni}$ in $\mathrm{NiO}$ ). Figure 1 shows the Fourier transform of $\mathrm{Ni}-\mathrm{K}$ edge of $\mathrm{NiO} / \gamma-\mathrm{Al}_{2} \mathrm{O}_{3}$ system. At the position corresponding to $\mathrm{Ni}-\mathrm{Ni}(2)$ peak of $\mathrm{NiO}$ there is no radial peak, meantime, at its left, a little radial peak appears, which doesn't change with the loading when it is less than maximum dispersionn amount. The coordination type of this peak will be discussed below.

Figure 2 shows the XAFS oscillating curves and the backscattering amplitudes functions of the structural peaks of $\mathrm{NiO} / \gamma-\mathrm{Al}_{2} \mathrm{O}_{3}$ corresponding to $\mathrm{Ni}$ $\mathrm{Ni}(1)$ and $\mathrm{Ni}-\mathrm{Ni}(2)$ in crystalline $\mathrm{NiO}$ respectively. The Figure 2-A shows that the maximum of backscattering amplitudes, frequencies and phase of oscillating curves of samples are agreed to those of $\mathrm{Ni}-\mathrm{Ni}(1)$ in $\mathrm{NiO}$, although the amplitudes reduce with decrease of $\mathrm{NiO}$ loading. The case of $\mathrm{Ni}-\mathrm{Ni}(3), \mathrm{Ni}-$ $\mathrm{Ni}(4)$ is similar to that also. But the situation of $\mathrm{Ni}-\mathrm{Ni}(2)$ coordination is different. When the content of $\mathrm{Ni}$ decreases, especially for the new radial peak mentioned above, the maximum of backscattering amplitudes shift to low $\mathrm{K}$ markedly and the frequency and phase of oscillating curves are different to $\mathrm{NiO}$ obviously either. It shows that the coordination shell in the dispersed phase is not

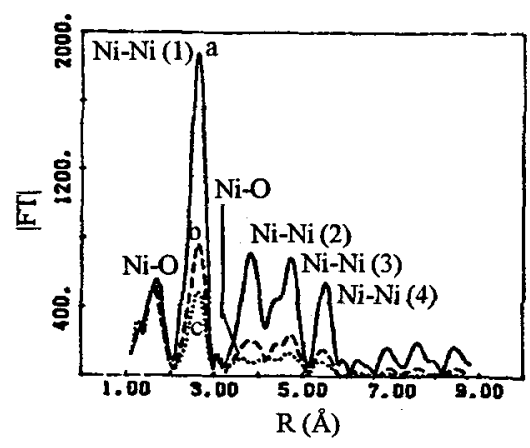
corresponding to $\mathrm{Ni}-\mathrm{Ni}(2)$ in crystalline phase. Maybe the peak is due to coordination shell of lighter atom. 
APCFT was carried out on the standard amplitude and phase shift obtained from corresponding Ni-Ni coordination shells of crystalline NiO. A part of results was shown in Figure 3. The absolute values and imaginary parts of Fourier transforms of Ni$\mathrm{Ni}(1,3,4)$ coordination peak at near same position. The peaks of imaginary parts are also symmetric. The absolute values and imaginary parts decrease with the decrease of $\mathrm{NiO}$ content regularly. But the situation of $\mathrm{Ni}-\mathrm{Ni}(2)$ coordination shell is different either. For the samples in which $\mathrm{NiO}$ is dispersed, the peaks of imaginary parts and absolute values misfit. The mentioned peak can be fit quite well by $\mathrm{Ni}-\mathrm{O}$ coordination. The results show further that when $\mathrm{NiO}$ is dispersed on the support, the $\mathrm{Ni}-\mathrm{Ni}$ coordination shell corresponding to the $\mathrm{Ni}-\mathrm{Ni}(2)$ in crystalline $\mathrm{NiO}$ disappears but a part of $\mathrm{Ni}-\mathrm{Ni}$ coordination shell corresponding to $\mathrm{Ni}-\mathrm{Ni}(1)$, even $\mathrm{Ni}-\mathrm{Ni}(3)$ coordination shell in $\mathrm{NiO}$ may remain still. The mentioned peak may belong to $\mathrm{Ni}-\mathrm{O}$ coordination. It is reasonable since in fact there is $\mathrm{Ni}-\mathrm{O}$ coordination shell in this position in crystalline spinel or $\mathrm{NiO}$. In spinel there is a part of $\mathrm{Ni}-\mathrm{Ni}(1)$ coordination shell but no $\mathrm{Ni}-\mathrm{Ni}(2)$ corresponding to $\mathrm{NiO}$. The dispersion system has formed a structure which has both similarity and difference to $\mathrm{NiAl}_{2} \mathrm{O}_{4}$ or $\mathrm{NiO}$. It is very consistent with the monolayer dispersion mode[3].
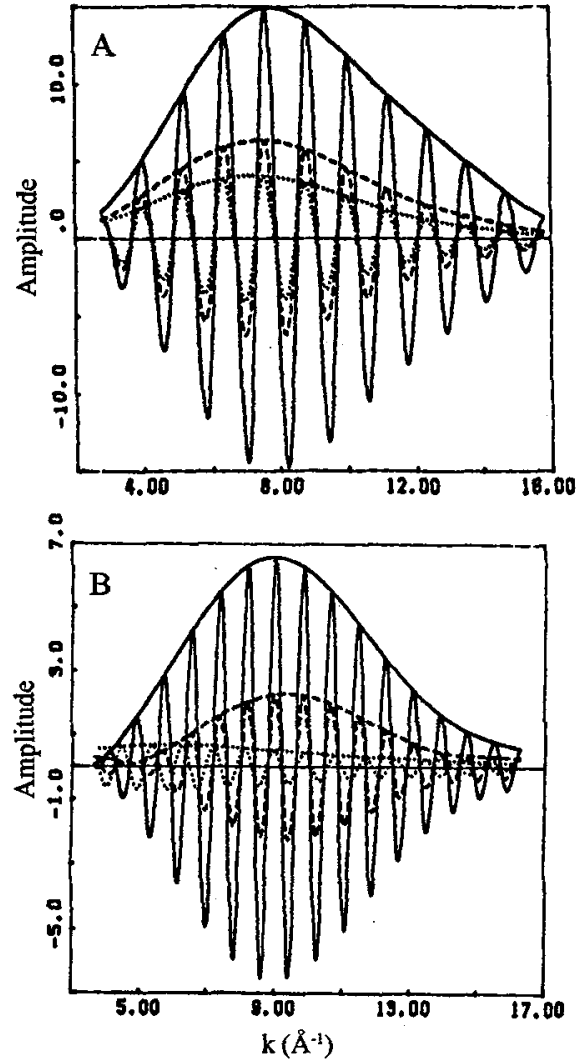

Figure 2: XAFS(solid line) and the backscattering amplitude(dotted line) $\left.\left(\mathrm{N} / \mathrm{R}^{2}\right) \mathrm{e}^{-2 \sigma^{2}} \mathrm{e}^{2 \mathrm{r} / 2}\right)$ term is included) curves corresponding to different $\mathrm{Ni}-\mathrm{Ni}$ coordination shells. A: Ni-Ni (1) coordination shell B: Ni-Ni (2) coordination shell Large amplitude: crystalline NiO

Middle amplitude: dispersed and crystalline $\mathrm{NiO}$ Small amplitude: dispersed $\mathrm{NiO}$
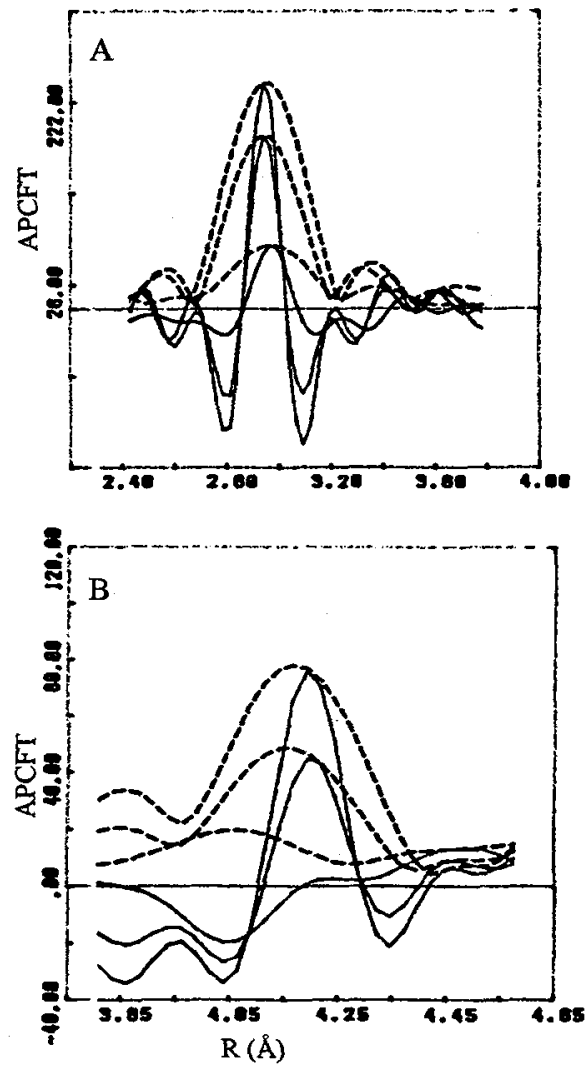

Figure 3: Comparison between imaginary part (solid line) and the absolute value (dotted line) of APCFT of different $\mathrm{Ni}-\mathrm{Ni}$ coordination shells

A: $\mathrm{Ni}-\mathrm{Ni}$ (1) coordination shell B: Ni-Ni (2) coordination shell

High peak: crystalline $\mathrm{NiO}$

Middle peak amplitude: dispersed and crystalline $\mathrm{NiO}$ Low peak: dispersed $\mathrm{NiO}$

\section{Acknowledgement}

Thanks for the help of BSRF of BEPC and Photon Factory in Japan.

\section{References}

[1] Farrel W. Lytle, Robert B. Greeger Edward C. Marques, Proc. 9th Intern. Congr. Catal. Vol 5, 54 (1988)

[2] Jun Dong, Kunquan Lu, Physical Review B 43, 8808 (1991)

[3] Cai Xiaohai, Liu Yingjun, Liu Zhiwei and Xie Youchang, Acta Physico-Chimica Sinica, Vol 10(1), 15 (1994) (in Chinese) 